Kyoto University,

Graduate School of Economics

Research Project Center Discussion Paper Series

Endogenous Phase Switch in Baumol's Service Paradox Model

\author{
Hiroaki Sasaki
}

Discussion Paper No. E-10-010

Research Project Center

Graduate School of Economics

Kyoto University

Yoshida-Hommachi, Sakyo-ku

Kyoto City, 606-8501, Japan

December 2010 


\title{
Endogenous Phase Switch in Baumol's Service Paradox Model
}

\author{
Hiroaki SASAKI \\ Graduate School of Economics, Kyoto University, Yoshida-honmachi, Sakyo-ku, Kyoto \\ 606-8501, Japan; e-mail: sasaki@econ.kyoto-u.ac.jp
}

\begin{abstract}
This paper develops a two-sector model that considers Baumol's service paradox. The paper simultaneously incorporates two ideas about technological progress in the model: (1) the consumption of services contributes to human capital accumulation and (2) the production of manufacturing leads to technological progress due to learning-by-doing. Accordingly, productivity growth in both services and manufacturing is endogenously determined. We show that initially, a shift in the employment share toward the services sector decreases the per capita real GDP growth rate, but at some point in time, the shift begins to increase the growth rate. Therefore, we observe an endogenous phase switch from a phase where the employment shift toward services depresses the economy to another where the employment shift promotes the economy.
\end{abstract}

Keywords: service paradox; structural change; endogenous productivity growth JEL classification: J21; J24; O11; O14; O30 


\section{Introduction}

Baumol (1967) predicts that in developed countries, the services employment share tends to increase. He explains this as follows. There are two sectors-a progressive sector (manufacturing) and a stagnant sector (services) - in the economy. Suppose that the productivity growth in services is lower than that in manufacturing. Suppose also that the ratio of manufacturing output to services output is constant. Then, though the price of services relative to that of manufacturing continues to rise, the demand for services keeps increasing because the output ratio (i.e., consumption ratio) is constant. Since the productivity growth in services is lower than that in manufacturing, more employment in services is necessary to meet the increasing demand for services, which results in a rise in the services employment share. Given the productivity growth differential and the constant demand ratio, the tendency toward a services economy is inevitable. ${ }^{1)}$ Indeed, we can easily see the employment shift toward services in developed countries.

In the same paper, Baumol makes an important prediction: as the employment share shifts toward services, the per capita real GDP growth rate will decline. He explains this as follows. The per capita real GDP growth rate is given by a weighted average of the productivity growth in manufacturing and the productivity growth in services with the weight being the corresponding employment share. Suppose that the employment share shifts toward services. Because the employment share of the services sector in which productivity growth is lower increases, the per capita real GDP growth continues to decline and converges to the productivity growth in services in the end. Hence, if the shift in the employment share toward services is inevitable, then the decline in the per capita real GDP growth is also inevitable.

However, does the shift in employment share toward services necessarily lower the per capita real GDP growth? For this issue, there are some theoretical contributions.

Pugno (2006) considers that the consumption of services augments human capital à la Lucas (1988). The consumption of health care and education services will lead to human capital accumulation. Accordingly, the consumption of services increases the productivity of workers, thereby resulting in an increase in the productivity of both manufacturing and services. This means that productivity growth is endogenized. He incorporated this human capital accumulation effect into Baumol's model, and showed that if this effect is relatively strong, the employment shift toward services increases, and not decreases, the per capita

1) In Baumol's (1967) model, labor is fully employed. In contrast, based on Pasinetti's (1993) pure labor economy model, Notarangelo (1999) presents a model with unemployment. She shows that given the productivity growth differential and price-non-elastic demand, employment shifts toward services as in Baumol (1967). 
real GDP growth.

De Vincenti (2007) reaches a conclusion similar to Pugno (2006). He assumes that both the growth rate of productivity in manufacturing and that in services are increasing functions of the employment share of services, and then, incorporates these specifications into Baumol's model. He also showed that the employment shift toward services increases the per capita real GDP growth. The basic idea of De Vincenti (2007) is similar to that of Pugno (2006). ${ }^{2)}$

These two theoretical studies pay attention to the external effects from the consumption and production of services and endogenize the productivity growth. If the productivity growth is exogenously given and the productivity growth in services is lower than that in manufacturing, then the employment shift toward services necessarily decreases the per capita real GDP growth. However, if the productivity growth is endogenously determined, then the employment shift toward services does not necessarily decrease the per capita real GDP growth.

Unlike in these researches, there exist theoretical studies wherein services are used as intermediate inputs for manufacturing. Oulton (2001) shows that if services are used as intermediate inputs for manufacturing, the employment shift toward services raises the per capita real GDP growth. In Oulton's model, services are only used as intermediate inputs, and hence, not used as final demand. In contrast, Sasaki (2007) shows that if services are used as both intermediate inputs and final demand, the employment shift toward services decreases the per capita real GDP growth in the long run. ${ }^{3)}$ In these two studies, productivity growth is exogenously given as in Baumol (1967).

The above studies pay attention to whether the employment shift toward services increases or decreases the per capita real GDP growth. In contrast, unlike in these studies, some theoretical studies show that the per capita real GDP growth is constant even if the employment share shifts toward services. These studies attempt to make structural changes compatible with Kaldor's (1961) stylized facts. Kaldor asserts that in developed countries, per capita real GDP growth is almost constant in the long run and there is no downward tendency.

Kongsamut, Rebelo, and Xie (2001) build a three sector (agriculture, manufacturing, and

2) However, under certain conditions, there occurs an inverted U-shaped relationship between the service employment share and the per capita real GDP growth. That is, initially, the per capita real GDP increases with the employment shift toward services, but at some point in time, it begins to decrease with the employment shift. This will be explained in detail in Section 4.

3) If the elasticity of substitution between labor input and services input in manufacturing is sufficiently larger than unity, then it is possible that the per capita real GDP growth increases up until some point in time with the employment shift toward services. However, even in that case, the per capita real GDP growth decreases in the long run. 
services) neoclassical growth model, and show that along the generalized balanced growth path, the per capita real GDP growth is constant although the employment share of each sector continues to change. ${ }^{4)}$ When deriving the result, they use a non-homothetic preference, which yields an endogenous structural change. Iscan (2010) modifies Kongsamut et al.'s (2001) model and examines how the interaction between the productivity growth differential à la Baumol, and Engel's law explains the long-run tendency of the services employment share in the US. He concludes that two thirds of the movements of the services employment share in reality can be explained by the two effects. These models, in contrast to Baumol's model that considers only labor input, consider capital accumulation. ${ }^{5)}$

As explained above, there are three types of views on the relationship between the employment shift toward services and the per capita real GDP growth. ${ }^{6)}$ A question then arises as to which view is consistent with reality.

Hartwig (2010) empirically treats this problem. He conducted an empirical analysis with regard to how the expenditure shift toward services such as health care and education affects the per capita real GDP growth rate. He analyzes 18 OECD countries during the period 1970-2005, and concludes that the expenditure shift lowers the per capita real GDP growth rate, which is broadly consistent with Baumol's (1967) statement. ${ }^{7)}$ Nordhaus (2008) empirically analyzes the US to ascertain Baumol's statement. As a result, he concludes that the employment shift toward services lowers the per capita real GDP growth. In contrast to these studies, Maroto-Sánchez and Cuadrado-Roura (2009) empirically investigate 37 OECD countries during the period 1980-2005, and conclude that the employment shift toward services has a positive effect on the per capita real GDP growth.

As stated above, different empirical studies have obtained contrasting results. There are several reasons why this is so. For example, the difference in the obtained results may be due to the use of different data for each empirical study. Moreover, there are many types of services, and accordingly, while some services have high productivity growth, others have low productivity growth.

However, in this paper, we propose that there is a nonlinear relationship between the

4) For the result where the per capita GDP growth becomes constant in spite of the structural changes, see also Ngai and Pissarides (2007), Acemoglu and Guerrieri (2008), and Foellmi and Zweimüller (2008).

5) Bonatti and Felice (2008) investigate a model in which capital is accumulated in both sectors, manufacturing productivity increases endogenously, and consumer preferences are non-homothetic.

6) The above explanations are based on the models of closed economy. Spilimbergo (1998) builds an open economy model, and shows that in a transition from a closed to an open economy, owing to a comparative advantage effect, the speed of employment shift toward services is faster in an open economy than in a closed economy, and consequently, the per capita real GDP growth declines much further in an open economy. Matsuyama (2009) presents a three-sector model, and shows that in a closed economy, the productivity growth differential results in structural changes, and that this is not necessarily the case in an open economy.

7) Hartwig (2010) shows that if Japan is excluded from the data sample, there is a statistically significant and long-lasting negative impact of this expenditure shift on economic growth. 
employment shift toward services and the per capita real GDP growth. This implies that because the relationship between the employment shift toward services and the per capita real GDP growth differs with country, a cross-country analysis treating different countries together will yield an ambiguous result. To show this, we present an extended Baumol's model that produces the conclusions of Baumol (1967), Pugno (2006), and De Vincenti (2007).

This paper incorporates both Pugno's (2006) idea that the consumption of services leads to the accumulation of human capital and Arrow's (1962) idea that the production of manufacturing leads to the productivity-increasing learning-by-doing effect. Accordingly, productivity growth in both sectors is endogenized. We show that initially, a shift in the employment share toward the services sector decreases the per capita real GDP growth rate but at some point in time, it begins to increase the per capita real GDP growth rate. Consequently, we obtain a U-shaped relationship between the employment share of services and the per capita real GDP growth.

This result means that whether the employment shift toward services increases or decreases the per capita real GDP growth depends on whether the economy is in a downward phase or an upward phase. Therefore, in our model, there occurs an endogenous phase switch from a phase where the employment shift toward services depresses the economy to another where the employment shift promotes the economy. Suppose that some countries lie in the downward phase while others lie in the upward phase. Then, an empirical analysis that treats these countries together is likely to yield an ambiguous result with regard to the relationship between the employment shift toward services and the per capita real GDP growth.

The remainder of this paper is organized as follows. Section 2 presents our model and investigates the mechanism that shifts the services employment, and the relationship between the employment shift and the per capita real GDP growth. Section 3 fully analyzes the dynamics of the model using numerical simulations. Section 4 compares our results with those obtained in previous studies. Section 5 concludes the paper.

\section{Model}

\subsection{Basic components}

First, we specify the firms' behavior. Consider an economy with two sectors: manufacturing $(m)$ and services $(s)$. Both sectors produce outputs using only labor inputs. We specify the 
production function of each sector as follows:

$$
\begin{aligned}
& Q_{m}=A_{m} L_{m}, \\
& Q_{s}=A_{s} L_{s},
\end{aligned}
$$

where $Q_{i}$ denotes the output $(i=m, s) ; A_{i}$, the labor productivity; and $L_{i}$, the employment. We assume that labor is fully employed. From this, we have $L_{m}+L_{s}=L$, where $L$ denotes the population of the labor force.

Suppose that labor is perfectly free to move between the two sectors. Then, the nominal wages in both sectors are equalized. We denote the wage as $w$. From the profit-maximizing and zero-profit conditions, we obtain the following equations:

$$
\begin{gathered}
p_{m}=\frac{w}{A_{m}}, \\
p_{s}=\frac{w}{A_{s}} .
\end{gathered}
$$

Consequently, the prices are equal to unit labor costs.

Next, we specify the consumers' behavior. We assume that a representative consumer solves the following optimization problem:

$$
\begin{aligned}
& \max _{c_{m}, c_{s}} u=\left[\alpha^{\frac{1}{\sigma}} c_{m}^{\frac{\sigma-1}{\sigma}}+(1-\alpha)^{\frac{1}{\sigma}}\left(c_{s}+\gamma\right)^{\frac{\sigma-1}{\sigma}}\right]^{\frac{\sigma}{\sigma-1}}, \\
& \text { s.t. } p_{m} c_{m}+p_{s} c_{s}=w,
\end{aligned}
$$

where $c_{i}$ denotes the per capita consumption $\left(c_{i}=C_{i} / L\right) ; \sigma$, the elasticity of substitution between the two types of consumption; $\alpha$, a parameter governing the weight of expenditure for manufacturing; and $\gamma$, a positive parameter governing home production. Such a nonhomothetic specification is also adopted in Iscan (2010). ${ }^{8)}$ When $\gamma=0$, the preference is homothetic, and hence, the income elasticities of the manufacturing consumption and the services consumption are unity. When $\gamma>0$, the preference is non-homothetic, and hence, the income elasticity of the manufacturing demand is less than unity and that of services demand is greater than unity. Introducing a positive $\gamma$ does not affect the dynamics of the employment share very much. However, it does affect the dynamics of the output ratio. Baumol (1967), when drawing the conclusion that the employment shift toward services decreases the per capita GDP growth, assumes that the output ratio remains constant over

8) The CES utility functions with $\gamma=0$ are adopted in Quibria and Harrigan (1996), Spilimbergo (1998), and De Vincenti (2007). 
time. ${ }^{9)}$ The assumption of $\gamma>0$ corresponds to Baumol's assumption.

By solving the maximization problem comprising equations (5) and (6), we obtain the following demand functions for manufacturing and services:

$$
\begin{aligned}
C_{m}= & \frac{\alpha}{1-\alpha}\left(\frac{p_{s}}{p_{m}}\right)^{\sigma}\left[\frac{w-\frac{\alpha}{1-\alpha} p_{m}\left(\frac{p_{s}}{p_{m}}\right)^{\sigma} \gamma}{p_{s}+\frac{\alpha}{1-\alpha} p_{m}\left(\frac{p_{s}}{p_{m}}\right)^{\sigma}}+\gamma\right] L, \\
C_{s}= & \frac{w-\frac{\alpha}{1-\alpha} p_{m}\left(\frac{p_{s}}{p_{m}}\right)^{\sigma} \gamma}{p_{s}+\frac{\alpha}{1-\alpha} p_{m}\left(\frac{p_{s}}{p_{m}}\right)^{\sigma}} \cdot L .
\end{aligned}
$$

The market clearing conditions for manufacturing and services are given by

$$
\begin{aligned}
Q_{m} & =C_{m}, \\
Q_{s} & =C_{s} .
\end{aligned}
$$

Substituting equations (1) and (7) in equation (9), and substituting equations (2) and (8) in equation (10), we obtain the each sector's employment share:

$$
\begin{aligned}
\frac{L_{m}}{L} & =\alpha A_{m}^{\sigma-1} \cdot \frac{1+\frac{\gamma}{A_{s}}}{\alpha A_{m}^{\sigma-1}+(1-\alpha) A_{s}^{\sigma-1}}, \\
\frac{L_{s}}{L} & =(1-\alpha) A_{s}^{\sigma-1} \cdot \frac{1+\frac{\gamma}{A_{s}}}{\alpha A_{m}^{\sigma-1}+(1-\alpha) A_{s}^{\sigma-1}}-\frac{\gamma}{A_{s}} .
\end{aligned}
$$

Here, let us assume that the growth rate of the labor productivity of each sector is exogenously given by $r_{i}$ and that $r_{m}>r_{s}$ as in Baumol (1967):

$$
g_{A_{m}} \equiv r_{m}>r_{s} \equiv g_{A_{s}}
$$

Hereafter, we denote the growth rate of a variable $x$ as $g_{x}$, where $g_{x}=\dot{x} / x=(d x / d t) / x$. Then, using equations (3) and (4), we find that the relative price of services, $p_{s} / p_{m}$, increases indefinitely (Baumol's cost disease). Moreover, by examining equations (11) and (12), we obtain the following proposition:

Proposition 1. Suppose that the growth rate of labor productivity in services is lower than

9) For the empirical plausibility of Baumol's assumption, see Sasaki (2007) and the literature cited therein. 
that in manufacturing. If the elasticity of substitution between the consumption of manufacturing and the consumption of services is less than unity, then the employment share of services $L_{s} / L$ will increase in the long run.

Proof. See appendix A.

Proposition 1 is the same as that in Baumol (1967). As mentioned above, Baumol assumes that the output ratio is constant. In contrast, we use a CES and non-homothetic preference.

The output of each sector is given by

$$
\begin{aligned}
Q_{m} & =\left[\alpha A_{m}^{\sigma} \cdot \frac{1+\frac{\gamma}{A_{s}}}{\alpha A_{m}^{\sigma-1}+(1-\alpha) A_{s}^{\sigma-1}}\right] L, \\
Q_{s} & =\left[(1-\alpha) A_{s}^{\sigma} \cdot \frac{1+\frac{\gamma}{A_{s}}}{\alpha A_{m}^{\sigma-1}+(1-\alpha) A_{s}^{\sigma-1}}-\gamma\right] L .
\end{aligned}
$$

From these equations, we obtain the output ratio (i.e., the consumption ratio):

$$
\frac{Q_{s}}{Q_{m}}=\frac{(1-\alpha) A_{s}^{\sigma} \cdot \frac{1+\frac{\gamma}{A_{s}}}{\alpha A_{m}^{\sigma-1}+(1-\alpha) A_{s}^{\sigma-1}}-\gamma}{1+\frac{\gamma}{A_{s}}} .
$$

Examining equation (16), we obtain the following proposition:

Proposition 2. Suppose that the growth rate of labor productivity in services is lower than that in manufacturing. Suppose also that the elasticity of substitution between the consumption of manufacturing and the consumption of services is less than unity. If $\gamma=0$, the output ratio $Q_{s} / Q_{m}$ will decline in the long run. The output ratio declines in the long run even if $\gamma>0$, but at a moderate rate.

Proof. See appendix B.

Proposition 2 states the long-run tendency of the output ratio. As mentioned earlier, Baumol (1967) assumes that the output ratio is constant, that is, $Q_{m} / Q_{s}=$ constant. On the other hand, we specify the utility function and assume that $\sigma<1$ and $\gamma>0$. These assumptions approximately correspond to Baumol's assumption. 


\subsection{Human capital accumulation and learning-by-doing}

In the preceding section, the growth rate of labor productivity for each sector is exogenously given. Here, in contrast, we endogenize the productivity growth of both sectors.

We assume that each sector's labor productivity is given by

$$
\begin{aligned}
A_{m} & =T_{m} \cdot h, \\
A_{s} & =h,
\end{aligned}
$$

where $T_{m}$ denotes the measure of productivity specific to manufacturing and $h$ denotes the level of human capital. Human capital $h$ affects both sectors' productivities because human capital is accumulated into workers who are free to move between the two sectors. From equations (17) and (18), we obtain the production functions $Q_{m}=T_{m}\left(h L_{m}\right)$ and $Q_{s}=h L_{s}$.

Next, based on the idea of Pugno (2006), we assume that human capital is accumulated through the consumption of services:

$$
\dot{h}=\delta c_{s}=\delta \frac{h L_{s}}{L}, \quad \delta>0
$$

where $\delta$ denotes a parameter governing the efficiency of human capital accumulation. In this specification, human capital accumulation is a linear function of accumulated human capital, which produces sustainable per capita real GDP growth. ${ }^{10)}$ Pugno (2006) considers two different cases: in one case, the consumption of services unintentionally leads to human capital accumulation whereas, in the other, agents intentionally consume services to accumulate human capital. In this paper, we adopt the unintentional human capital accumulation case for ease of analysis.

Finally, we assume that the manufacturing-specific productivity $T_{m}$ is an increasing function of knowledge stock $K_{m}$ :

$$
T_{m}=K_{m}^{\phi}, \quad \phi>0,
$$

where $\phi$ denotes the elasticity of $T_{m}$ with respect to $K_{m}$. Following the idea of Arrow (1962), we assume that the knowledge stock depends on the production experience that is accumulated until now; we specify the knowledge stock as follows:

$$
K_{m}=\exp \left[\int_{-\infty}^{t} \frac{L_{m}(\tau)}{L(\tau)} d \tau\right]
$$

10) However, the effect of human capital accumulation might weaken as the consumption of services increases. For this case, see appendix C. 
Note that the production experience $K_{m}$ is measured by $L_{m} / L$. We use the manufacturing employment share, and not the level of manufacturing employment, to ascertain that the dynamics of the model holds even when the labor force grows. In addition, we use manufacturing employment, and not manufacturing output, for the following two reasons. ${ }^{11}$ ) First, in our model, labor is the sole factor of production, and then, an increase in output has a one-to-one relationship with an increase in employment. Therefore, for simplicity, we measure production experience by the employment of manufacturing, not by the output of manufacturing. Second, with our specification, the productivity growth in each sector leads to a function that depends only on employment share. For this reason, we can easily compare our model with Pugno's (2006) and De Vincenti's (2007) models, in which productivity growth is a function that depends only on employment share.

From equations (20) and (21), the flow of $T_{m}$ leads to

$$
\dot{T}_{m}=\left(\phi \frac{L_{m}}{L}\right) T_{m}
$$

Differentiating equations (17) and (18) with respect to time and substituting equations (19) and (22) in the resultant expressions, we obtain the growth rate of labor productivity for each sector as follows:

$$
\begin{aligned}
& g_{A_{s}}=\delta\left(1-\frac{L_{m}}{L}\right)=\delta \frac{L_{s}}{L}, \\
& g_{A_{m}}=\delta+(\phi-\delta) \frac{L_{m}}{L}=\phi-(\phi-\delta) \frac{L_{s}}{L} .
\end{aligned}
$$

From these equations, we always have $g_{A_{m}} \geq g_{A_{s}} \cdot{ }^{12)}$ Therefore, we obtain the result that corresponds to Baumol's (1967) assumption, $r_{m}>r_{s}$.

The productivity growth of services is an increasing function of the employment share of services. We now turn to the productivity growth of manufacturing. Let us pay attention to the values of $\delta$ and $\phi$. If $\phi>\delta, g_{A_{m}}$ is a decreasing function of $L_{s} / L$. If, in contrast, $\phi<\delta$, $g_{A_{m}}$ is an increasing function of $L_{s} / L$. Recall that $\delta$ denotes the efficiency of human capital accumulation with respect to services consumption and $\phi$ denotes the elasticity of the manufacturing-specific productivity with respect to manufacturing production. Therefore, which effect dominates determines whether the growth rate of manufacturing labor productivity becomes a decreasing or an increasing function of the employment share of services. Figures 1 and 2 show the relationships between $g_{A_{i}}$ and $L_{S} / L$.

In Pugno (2006) and De Vincenti (2007), the growth rates of productivity for both sec-

11) For the case where production experience is measured by the output of manufacturing, see appendix D.

12) If $\phi=\delta$, the growth rate of the manufacturing labor productivity is $\delta$, which is constant. 
tors are increasing functions of the employment share of services. In our model, in contrast, the manufacturing productivity growth is either increasing or decreasing in the services employment share. Nevertheless, as we will explain later, this does not affect our main results. What is important is that the productivity growth differential $g_{A_{m}}-g_{A_{s}}$ decreases with the shift in the employment share toward services: $g_{A_{m}}-g_{A_{s}}=\phi\left[1-\left(L_{s} / L\right)\right]$. This finding is consistent with the empirical data shown in Bosworth and Triplett (2007), who calculate the labor productivity growth and the total factor productivity growth for manufacturing and services in the US. They show that the productivity growth differentials between the two sectors decrease with time. ${ }^{13)}$

[Figures 1 and 2 to be inserted here]

\subsection{Per capita real GDP growth}

Now, we derive the per capita real GDP growth rate. To consider economic growth in real terms, we must eliminate the effect of price variations. The per capita real GDP growth rate $g$ can be defined as follows:

$$
g(t)=\frac{p_{m}(t) \dot{Q}_{m}(t)+p_{s}(t) \dot{Q}_{s}(t)}{p_{m}(t) Q_{m}(t)+p_{s}(t) Q_{s}(t)}=g_{A_{m}}(t) \frac{L_{m}(t)}{L(t)}+g_{A_{s}}(t) \frac{L_{s}(t)}{L(t)} .
$$

This implies that $g$ is the weighted average of the growth rate of labor productivity for each sector with the weight being the corresponding employment share.

In our model, $g$ is calculated as follows:

$$
\begin{aligned}
g & =\left(g_{T_{m}}+g_{h}\right) \frac{L_{m}}{L}+g_{h} \frac{L_{s}}{L} \\
& =\phi\left(\frac{L_{s}}{L}-\frac{2 \phi-\delta}{2 \phi}\right)^{2}+\delta\left(\frac{4 \phi-\delta}{4 \phi}\right) .
\end{aligned}
$$

Hence, $g$ is a quadratic function with respect to the employment share of services. Examining equation (27), we obtain the following proposition:

Proposition 3. If $2 \phi<\delta$, then the per capita real GDP growth increases with the employment shift toward services. If $2 \phi>\delta$, then the per capita real GDP growth decreases until the services employment share reaches $\left(L_{s} / L\right)^{*}=\frac{2 \phi-\delta}{2 \phi}$, and from then onward, it increases with the employment shift toward services, finally converging to $g=\delta$.

13) They estimated that the productivity growth differentials in terms of the labor productivity are 1.3 (19871995), 0.7 (1995-2000), and 0.5 (2000-2005), and those in terms of the total factor productivity are 1.3 (1987-1995), 1 (1995-2000), and 0.4 (2000-2005). 
Proposition 3 states that there exists a U-shaped relationship between the employment share of services and the per capita real GDP growth. Suppose that the initial value of the services employment share is sufficiently small. Then, as the services employment share increases, the per capita real GDP growth decreases. However, when the services employment share exceeds the threshold value given by $\left(L_{s} / L\right)^{*}$, the per capita real GDP growth increases and finally converges to $g=\delta$. Whether the relationship between $L_{s} / L$ and $g$ leads to a Ushaped curve depends on the relative size of the effect of human capital accumulation due to the consumption of services. If this effect is relatively strong, the shift in the employment share of services continues to increase the per capita real GDP growth monotonically. On the other hand, if the effect is relatively weak, we have a U-shaped relationship. Figures 3-5 show the relationship between the services employment share and the per capita real GDP growth for both cases.

[Figures 3, 4, and 5 to be inserted here]

In our model, the growth rate of labor productivity in manufacturing is always larger than that in services, which is the same as in Baumol (1967). Nevertheless, there exists a phase in which the shift in the employment share toward services increases the per capita real GDP growth, which is interesting.

As explained above, whether $\phi$ is larger than $\delta$ or vice versa determines whether $g_{A_{m}}$ is an increasing or a decreasing function of $L_{s} / L$. If $\phi>\delta$, the manufacturing productivity growth is a decreasing function of the services employment share. In this case, we necessarily have $2 \phi>\delta$, and hence we obtain a U-shaped relationship between $L_{s} / L$ and $g$ in Proposition 3 (see Figure 5). If $\phi<\delta$, the manufacturing productivity growth is an increasing function of the services employment share. Even then, we can have $2 \phi>\delta$, which produces a U-shaped relationship between $L_{S} / L$ and $g$ (see Figure 4). If $\delta \rightarrow 0, g$ becomes a decreasing function of $L_{s} / L$, which produces the same result as in Baumol (1967) that a shift in the employment share toward services decreases the per capita real GDP growth.

Why do we obtain such a U-shaped relationship? Rewriting equation (25), we obtain the following relations:

$$
\begin{aligned}
g & =g_{A_{m}}-\underbrace{\left(g_{A_{m}}-g_{A_{s}}\right)}_{+} \frac{L_{s}}{L} \\
& =g_{A_{m}}-\underbrace{\phi\left(1-\frac{L_{s}}{L}\right)}_{g_{A_{m}}-g_{A_{s}}} \frac{L_{s}}{L} .
\end{aligned}
$$

Ceteris paribus, as long as $g_{A_{m}}>g_{A_{s}}$, a rise in $L_{s} / L$ has a negative effect on the per capita real GDP growth (see equation (28)). Note that in our model, the productivity growth dif- 
ferential $g_{A_{m}}-g_{A_{s}}$ is a decreasing function of the services employment share. Hence, as the employment share shifts toward services, the negative effect of the increase in $L_{s} / L$ on the per capita real GDP growth diminishes. As stated above, the first term in the right-hand side (RHS), $g_{A_{m}}$, can be an increasing or decreasing function of the services employment share. However, in either case, we always have $g_{A_{m}}>0$. Therefore, when the services employment share is small, the negative effect of the second term in the RHS is relatively large, and hence a shift in the employment share toward services decreases the per capita real GDP growth. On the other hand, when the services employment share is large, the positive effect of the first term in the RHS is relatively large, and hence a shift in the employment share toward services increases the per capita real GDP growth. Using the same reasoning, we can explain why the speed of switch from a downward phase to an upward phase is faster when $\phi<\delta$ than when $\phi>\delta$ (see Figures 4 and 5).

\section{Full dynamics and numerical examples}

From the above analysis, we obtained three propositions. However, the analysis is not complete. When deriving Propositions 1 and 2, we assume that the growth rates of labor productivity for both sectors are exogenously given. When deriving Proposition 3, we assume that the employment share of services increases with time. In our model, the productivity growth and the employment share are dependent on each other. Therefore, we must analyze the dynamics of the employment share and productivity growth simultaneously.

The dynamics are summarized as follows:

$$
\begin{aligned}
& \dot{A_{s}}=\delta A_{s} \frac{L_{s}}{L}, \\
& \dot{A}_{m}=A_{m}\left[\phi-(\phi-\delta) \frac{L_{s}}{L}\right], \\
& \frac{L_{s}}{L}=(1-\alpha) A_{s}^{\sigma-1} \cdot \frac{1+\frac{\gamma}{A_{s}}}{\alpha A_{m}^{\sigma-1}+(1-\alpha) A_{s}^{\sigma-1}}-\frac{\gamma}{A_{s}} .
\end{aligned}
$$

Substituting equation (32) in equations (30) and (31), we obtain a system of two differential equations with respect to $A_{s}(t)$ and $A_{m}(t)$.

Because the above system is nonlinear and somewhat complicated, we use numerical simulations to analyze the dynamics. By examining the dynamics of $A_{m}$ and $A_{s}$, we can know the behaviors of the other endogenous variables. Here, we consider only the case of $\sigma<1$ in which the employment share of services increases with time. We set the parameters as in Table 1. In Case 1, we have $\phi>\delta$, and in Case 2, we have both $\phi<\delta$ and $2 \phi>\delta$. 
Moreover, we set the initial values of both $A_{m}$ and $A_{s}$ to unity.

[Table 1 to be inserted here]

Figures 6-11 show the results of the numerical simulations. ${ }^{14)}$ These figures give the time path of each variable when the elasticity of substitution $\sigma$ varies from 0.1 to 0.9 in intervals of 0.1 .

In Cases 1 and 2, the services employment share increases with time, and the per capita real GDP growth decreases initially and then increases. ${ }^{15)}$ However, there is a marked difference between Figures 7 and 9. The switching time from a downward phase to an upward phase is shorter in Figure 9 than in Figure 7. This is because the threshold values $\left(L_{s} / L\right)^{*}$ are different between Cases 1 and $2-\left(L_{S} / L\right)^{*}=0.7$ in Case 1 and $\left(L_{s} / L\right)^{*}=0.375$ in Case 2 -which are shown in Figures 6 and 8 as horizontal real lines. As can be seen from Figures 6 and 8, the time path of the services employment share does not differ much. However, the speed with which the per capita real GDP growth switches from a downward phase to an upward phase is faster in Case 2 than in Case 1 because $\left(L_{S} / L\right)^{*}$ is smaller in Case 2 than in Case 1.

The size of the elasticity of substitution substantially affects the time path of the output ratio $Q_{s} / Q_{m}$. As mentioned in Proposition 2, the output ratio declines in the long run. However, the speed of the decline depends crucially on the size of the elasticity of substitution. As Figures 10 and 11 show, in both Cases 1 and 2, the smaller the elasticity of substitution, the more moderate will be the speed of the decline in the output ratio.

[Figures 6, 7, 8, and 9 to be inserted here]

\section{Comparison and discussion}

In this section, we compare our results with those obtained in previous studies. In the comparison, we focus our attention on the mechanism through which various results are generated. Note that the notations of parameters in other models are adjusted as per our model as much as possible.

\footnotetext{
14) For the numerical simulations, we use Mathematica 7.

15) In this paper, we focus our attention on the per capita real GDP growth. On the other hand, we can also consider the growth rate of the level of utility $u$. From numerical simulations, we find that in Case 1 , the growth rate of $u$ shows a time path similar to the growth rate of $g$. In contrast, in Case 2, it is possible that the growth rate of $u$ continues to increase with time: the growth rate of $u$ is not U-shaped. In either case, the time paths of the growth rates of $g$ and $u$ coincide if we compute for a sufficiently long time.
} 
In Baumol (1967), the per capita real GDP growth rate is given by

$$
\begin{aligned}
g_{\text {Baumol }} & =r_{m} \frac{L_{m}}{L}+r_{s} \frac{L_{s}}{L} \\
& =r_{m}-\left(r_{m}-r_{s}\right) \frac{L_{s}}{L} .
\end{aligned}
$$

If $r_{m}>r_{s}$ and $L_{s} / L$ increases, then $g_{\text {Baumol }}$ decreases with time and finally converges to $g_{\text {Baumol }}=r_{s}$.

In Pugno (2006), the production function of manufacturing is given by $Q_{m}=\left(h L_{m}\right) e^{r_{m} t} \cdot{ }^{16)}$ That is, we have $T_{m}=e^{r_{m} t}$, where $r_{m}$ is exogenously given. The production function of services is the same as that in our model. The growth rates of labor productivity are given by $g_{A_{m}}=r_{m}+\delta L_{s} / L$ and $g_{A_{s}}=\delta L_{s} / L$. The per capita real GDP growth is given by

$$
\begin{aligned}
g_{\text {Pugno }} & =\left(r_{m}+\delta \frac{L_{s}}{L}\right) \frac{L_{m}}{L}+\left(\delta \frac{L_{s}}{L}\right) \frac{L_{s}}{L} \\
& =r_{m}+\left(\delta-r_{m}\right) \frac{L_{s}}{L} .
\end{aligned}
$$

Note that in Pugno's (2006) model, we always have $g_{A_{m}}>g_{A_{s}}$. If $r_{m}<\delta$, that is, the exogenous growth rate of labor productivity for manufacturing exceeds the efficiency of human capital accumulation, then $g_{\text {Pugno }}$ continues to decline with the shift in the employment share toward services. This is the same result as that in Baumol (1967). However, if $r_{m}<\delta$, that is, the efficiency of human capital accumulation exceeds the exogenous growth rate of labor productivity for manufacturing, then $g_{\text {Pugno }}$ continues to rise with the shift in the employment share toward services. In either case, we obtain a linear relationship between $L_{s} / L$ and $g$. Moreover, the per capita real GDP growth converges to $g_{\text {Pugno }}=\delta$.

In De Vincenti (2007), the growth rates of labor productivity for both sectors are given by $g_{A_{m}}=\alpha\left(L_{s} / L\right)^{\beta}$ and $g_{A_{s}}=\delta\left(L_{s} / L\right) .{ }^{17)}$ Here, $\alpha, \beta$, and $\delta$ are all positive constants. The per capita real GDP growth is given by

$$
\begin{aligned}
g_{\mathrm{DV}} & =\alpha\left(\frac{L_{s}}{L}\right)^{\beta} \frac{L_{m}}{L}+\left(\delta \frac{L_{s}}{L}\right) \frac{L_{s}}{L} \\
& =(\delta-\alpha)\left(\frac{L_{s}}{L}\right)^{2}+\alpha \frac{L_{s}}{L} \quad \text { when } \beta=1 .
\end{aligned}
$$

De Vincenti (2007) makes an assumption that corresponds to $0<\beta<1$. However, this assumption is not essential, and as such, we assume that $\beta=1$ for ease of exposition. In

16) In fact, the production function is given by $Q_{m}=b\left(h L_{m}\right) e^{r_{m} t}$, that is, a constant term $b$ is added. However, this term is not essential, and hence, we use $b=1$ for simplicity.

17) The productivity growth in De Vincenti (2007) is written in a general form, but for ease of exposition, it is written in a specific form in our paper. 
addition, he makes an assumption that corresponds to $\alpha>\delta$, which we also adopt. ${ }^{18)}$

If $\alpha>\delta$ and $\alpha<2 \delta, g_{\mathrm{DV}}$ continues to increase with $L_{s} / L$. If $\alpha>2 \delta, g_{\mathrm{DV}}$ increases with $L_{s} / L$ initially, but once $L_{s} / L$ reaches $\alpha /[2(\alpha-\delta)], g_{\mathrm{DV}}$ begins to decline with $L_{s} / L$. Therefore, we obtain an inverted U-shaped relationship between $L_{s} / L$ and $g$, which is shown in Figure 12. In either case, the per capita real GDP growth converges to $g_{\mathrm{DV}}=\delta$.

[Figure 12 to be inserted here]

The difference between the results in our model and De Vincenti's (2007) model lies in the differences in the specification of the productivity growth for manufacturing because the specification of the productivity growth for services in both models is identical. ${ }^{19)}$ In his model, when $\alpha>\delta$, the productivity growth differential $g_{A_{m}}-g_{A_{s}}$ becomes an increasing function of the employment share of services (recall equation (28)). This means that the larger the employment share of services, the stronger will be the negative effect of the rise in $L_{s} / L$ on the per capita real GDP growth. ${ }^{20)}$ Therefore, it is possible that the shift in the employment share toward services decreases the per capita real GDP growth in the long run.

\section{Concluding Remarks}

In this paper, we built a model in which productivity grows endogenously for both manufacturing and services, and investigated the relationship between the shift in the employment share toward services and the per capita real GDP growth. We adopted two ideas simultaneously: (1) the consumption of services contributes to human capital accumulation and (2) the learning-by-doing effect is present in manufacturing.

Our analysis shows that initially, the employment shift toward services decreases the per capita real GDP growth rate, but from some point in time onward, it gradually increases the

18) If, in contrast, we assume that $\alpha<\delta$, it is possible that the growth rate of labor productivity for services exceeds that for manufacturing, which seems to contradict the observation in the real world. Hence, we assume that $\alpha>\delta$.

19) In fact, by modifying De Vincenti's model a little, we obtain a U-shaped relationship between $L_{s} / L$ and $g$. We add a constant term to the productivity growth in manufacturing: $g_{A_{m}}=\alpha\left(L_{s} / L\right)^{\beta}+\varepsilon$, where $\varepsilon$ is a positive constant. If $\alpha<\delta, \alpha<\varepsilon$, and $\alpha+\varepsilon>\delta$, then $g_{\mathrm{DV}}$ is a convex downward parabola with a positive axis. Accordingly, we obtain a U-shaped relationship. However, this specification seems rather arbitrary. In our model, we use a more reasonable specification to obtain a U-shaped relationship between $L_{s} / L$ and $g$.

20) By modifying our model a little, we obtain an inverted U-shaped relationship between $L_{s} / L$ and $g$ similar to what De Vincenti has obtained. Suppose that the manufacturing productivity is given by $A_{m}=T_{m} h^{1+\beta}$, where $\beta$ is a positive constant. Then, the production function of manufacturing yields $Q_{m}=T_{m} h^{\beta}\left(h L_{m}\right)$. This specification implies that human capital accumulation exerts a positive externality in manufacturing and that $\beta$ captures the extent of this externality. If $\beta<1$, we obtain the same results as those in the text. In contrast, if $\beta>1$, we obtain an inverted U-shaped relationship between the services employment share and the per capita real GDP growth depending on conditions. Nevertheless, the case in which the externality is larger than unity seems rather extreme. 
growth rate. This result is consistent with both Baumol's (1967) view that the employment shift toward services decreases the per capita real GDP growth and Pugno's (2006) view that the employment shift toward services increases the per capita real GDP growth. Accordingly, our model can explain the two views simultaneously. As the employment share of services increases, the learning-by-doing effect in manufacturing decreases. On the other hand, as the employment share of services increases, the human capital accumulation effect due to the consumption of services increases. The interaction of these two opposing effects produces a U-shaped relationship between the employment share of services and the per capita real GDP growth rate.

This result suggests that when conducting a cross-country analysis to ascertain the relationship between the employment shift toward services and the per capita real GDP growth, we must pay considerable attention as the relationship differs depending on whether a country is in a downward phase or an upward phase. Consequently, if we treat all countries together, we will obtain an ambiguous relationship between the employment shift toward services and the per capita real GDP growth.

Finally, if the services employment share continues to increase, then the per capita real GDP growth converges to the services productivity growth in the long run. Therefore, to promote economic growth, we must raise the services productivity, which is a characteristic common to all models that appear after Baumol's (1967) insightful contribution. 


\section{References}

Acemoglu, D., Guerrieri, V., 2008. Capital deepening and nonbalanced economic growth. Journal of Political Economy 116 (3), 467-498.

Arrow, K. J., 1962. The economics implications of learning by doing. Review of Economic Studies 29 (3), 155-173.

Baumol, W., 1967. Macroeconomics of unbalanced growth: the anatomy of urban crisis. American Economic Review 57 (3), 415-426.

Bonatti, L., Felice, G., 2008. Endogenous growth and changing sectoral composition in advanced economies. Structural Change and Economic Dynamics 19 (2), 109-131.

Bosworth, B. P., Triplett, J. E., 2007. The early 21 st century U.S. productivity expansion is still in services. International Productivity Monitor 14 (Spring), 3-19.

De Vincenti, C., 2007. Baumol's disease, production externalities and productivity effects of intersectoral transfers. Metroeconomica 58 (3), 396-412.

Foellmi, R., Zweimüller, J., 2008. Structural change, Engel's consumption cycles and Kaldor's facts of economic growth. Journal of Monetary Economics 55 (7), 1317-1328.

Hartwig, J., 2008. Has health capital formation cured Baumol's disease?-Panel Granger causality evidence for OECD countries. KOF Working Papers No. 206.

Iscan, T., 2010. How much can Engel's law and Baumol's disease explain the rise of service employment in the United States? The B.E. Journal of Macroeconomics 10 (1), Contributions, Article 26.

Kaldor, N., 1961. Capital accumulation and economic growth. In: Lutz, F. A., Hague, D. C. (Eds.), The Theory of Capital. Macmillan, London.

Kongsamut, P., Rebelo, S., Xie, D., 2001. Beyond balanced growth. Review of Economic Studies 68 (4), 869-882.

Lucas, R. E., 1988. On the mechanics of economic development. Journal of Monetary Economics 22 (1), 3-42.

Maroto-Sánchez, A., Cuadrado-Roura, J. R., 2009. Is growth of services an obstacle to productivity growth? A comparative analysis. Structural Change and Economic Dynamics 20 (4), 254-265. 
Matsuyama, K., 2009. Structural change in an interdependent world: a global view of manufacturing decline. Journal of European Economic Association 7 (2-3), 478-486.

Ngai, R. L., Pissarides, C. A., 2007. Structural change in a multisector model of growth. American Economic Review 97 (1), 429-443.

Nordhaus, W. D., 2008. Baumol's diseases: a macroeconomic perspectives. The B.E. Journal of Macroeconomics 8 (1), Contributions, Article 9.

Notarangelo, M., 1999. Unbalanced growth: a case of structural dynamics. Structural Change and Economic Dynamics 10 (2), 209-223.

Oulton, N., 2001. Must the growth rate decline? Baumol's unbalanced growth revisited. Oxford Economic Papers 53 (4), 605-627.

Pasinetti, L. L., 1993. Structural Economic Dynamics: A Theory of Economic Consequences of Human Learning. Cambridge University Press, Cambridge.

Pugno, M., 2006. The service paradox and endogenous economic growth. Structural Change and Economic Dynamics 17 (1), 99-115.

Quibria, M. G., Harrigan, F., 1996. Demand bias and structural change. Kyklos 49 (2), 205-213.

Sasaki, H., 2007. The rise of service employment and its impact on aggregate productivity growth. Structural Change and Economic Dynamics 18 (4), 438-459

Spilimbergo, A., 1998. Deindustrialization and trade. Review of International Economics $6(3), 450-460$. 


\section{Appendix}

\section{A Proof of proposition 1}

Let us rewrite equation (11) as follows:

$$
\frac{L_{m}}{L}=\frac{\alpha\left(1+\frac{\gamma}{A_{s}}\right)}{\alpha+(1-\alpha)\left(\frac{A_{m}}{A_{s}}\right)^{1-\sigma}} .
$$

First, the numerator decreases as $A_{s}$ increases. Second, $A_{m}$ becomes larger than $A_{s}$ with time when $r_{m}>r_{s}$, and then, the denominator increases with time because $1-\sigma>0$. For these reasons, $L_{m} / L$ decreases with time, which implies that $L_{s} / L$ increases with time.

\section{B Proof of proposition 2}

Let us denote the terms that simultaneously appear in both the denominator and the numerator in equation (16) as $\Theta$. Then, we can rewrite the output ratio as follows:

$$
\frac{Q_{s}}{Q_{m}}=\frac{(1-\alpha) \Theta A_{s}^{\sigma}-\gamma}{\alpha \Theta A_{m}^{\sigma}}, \quad \text { where } \Theta \equiv \frac{1+\frac{\gamma}{A_{s}}}{\alpha A_{m}^{\sigma-1}+(1-\alpha) A_{s}^{\sigma-1}} .
$$

Given that $r_{m}>r_{s}, A_{m}$ becomes larger than $A_{s}$ with time. $\Theta$, though not constant, appears simultaneously in both the denominator and the numerator, and thus has no effect on the long-run trend of the output ratio. Accordingly, the denominator becomes larger than the numerator in the long run, which implies that $Q_{s} / Q_{m}$ declines in the long run.

Next, we divide both the denominator and the numerator with $A_{s}^{\sigma}$ :

$$
\frac{Q_{s}}{Q_{m}}=\frac{(1-\alpha) \Theta-\frac{\gamma}{A_{s}^{\sigma}}}{\alpha \Theta\left(\frac{A_{m}}{A_{s}}\right)^{\sigma}}
$$

When $\gamma>0$, that is, the preference is non-homothetic, $\gamma / A_{s}^{\sigma}$ in the numerator decreases with $A_{s}$. This increases the numerator. When $\gamma=0$, this effect vanishes, and the denominator increases with time. As such, when $\gamma>0$, the decreasing effect on $Q_{s} / Q_{m}$ is weaker as compared to when $\gamma=0$, which implies that the long-run decline in $Q_{s} / Q_{m}$ is more moderate 
when $\gamma=0$.

\section{Alternative specification for human capital accumula- tion}

In the text, based on Pugno (2006), we assume that human capital accumulation is a linear function of the consumption of services. However, it is possible that the effect of human capital accumulation weakens as the consumption of services increases. In this case, we can use the following specification:

$$
\dot{h}=\delta c_{s}^{\psi}, \quad 0<\psi \leq 1 .
$$

Pugno (2006) corresponds to the case of $\psi=1$ in this specification.

The productivity of each sector and the per capita GDP growth are given by

$$
\begin{aligned}
\dot{A}_{s} & =\delta\left(\frac{A_{s} L_{s}}{L}\right)^{\psi}, \\
\dot{A}_{m} & =A_{m}\left[\phi\left(1-\frac{L_{s}}{L}\right)+\delta\left(\frac{L_{s}}{L}\right)^{\psi} A_{s}^{\psi-1}\right], \\
g & =\frac{L_{m}}{L}\left[\phi\left(1-\frac{L_{s}}{L}\right)+\delta\left(\frac{L_{s}}{L}\right)^{\psi} A_{s}^{\psi-1}\right]+\frac{L_{s}}{L} \delta\left(\frac{L_{s}}{L}\right)^{\psi} A_{s}^{\psi-1} .
\end{aligned}
$$

Using numerical simulations, we find that the per capita GDP growth decreases with the employment share of services.

\section{Alternative specification for learning by doing}

In equation (21) of the text, production experience is measured by the employment of manufacturing, not by the output of manufacturing. Let us see what happens if we measure production experience by the output of manufacturing, not the employment of manufacturing. If we use $Q_{m} / L$ instead of $L_{m} / L$, we have

$$
K_{m}=\exp \left[\int_{-\infty}^{t} \frac{Q_{m}(\tau)}{L(\tau)} d \tau\right]
$$


Using this equation, we obtain the growth rate of productivity of manufacturing as follows:

$$
g_{A_{m}}=\phi A_{m}-(\phi-\delta) \frac{L_{s}}{L}
$$

In this case, analytical treatment becomes much complicated. By conducting numerical simulations, we find that in both Cases 1 and 2, the employment share of services increases with time. Moreover, we find that in both Cases 1 and 2, the growth rate of per capita real GDP increases at first, decreases from some point in time on, and then converges to $g=\delta$. That is, we obtain an inverted U-shaped relationship, not a U-shaped relationship, between the employment share of services and the growth rate of per capita real GDP.

The reason why we obtain the above result is that the productivity growth differential $g_{A_{m}}-g_{A_{s}}$ that appears in equation (28) becomes an increasing function, not a decreasing function, of $L_{s} / L$. This implies that the productivity growth differential increases with time. However, this is not consistent with the empirical finding of Bosworth and Triplett (2007). 


\section{Figures and table}
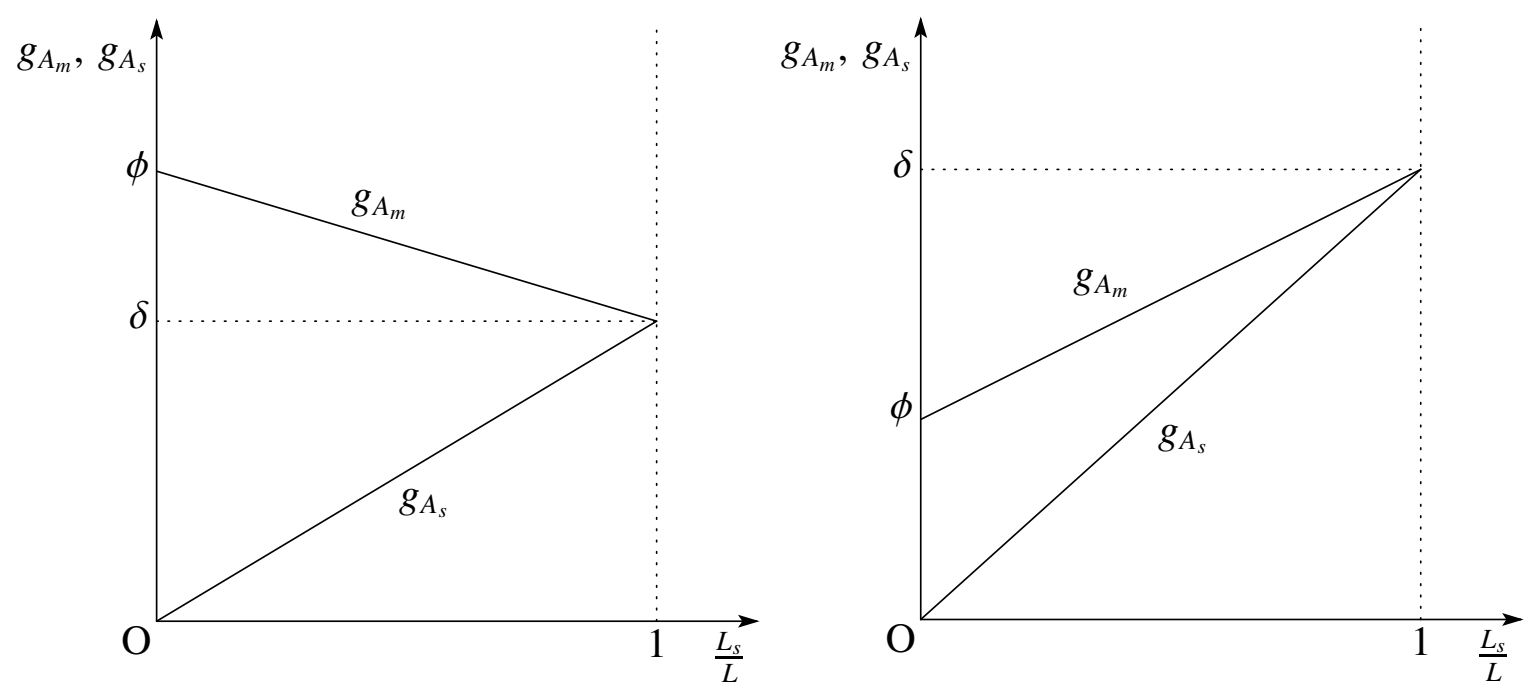

Figure 1: Relationship between $g_{A_{i}}$ and $L_{s} / L$ Figure 2: Relationship between $g_{A_{i}}$ and $L_{s} / L$ when $\phi>\delta$ when $\phi<\delta$ 


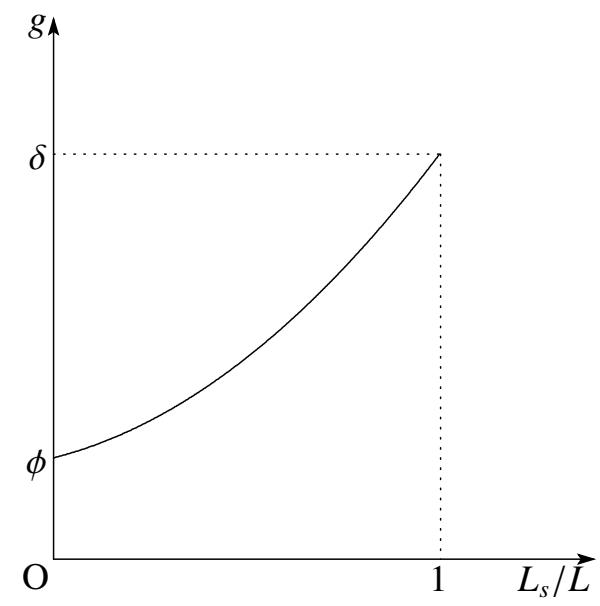

Figure 3: Relationship between $g$ and $L_{s} / L$ when $2 \phi<\delta$
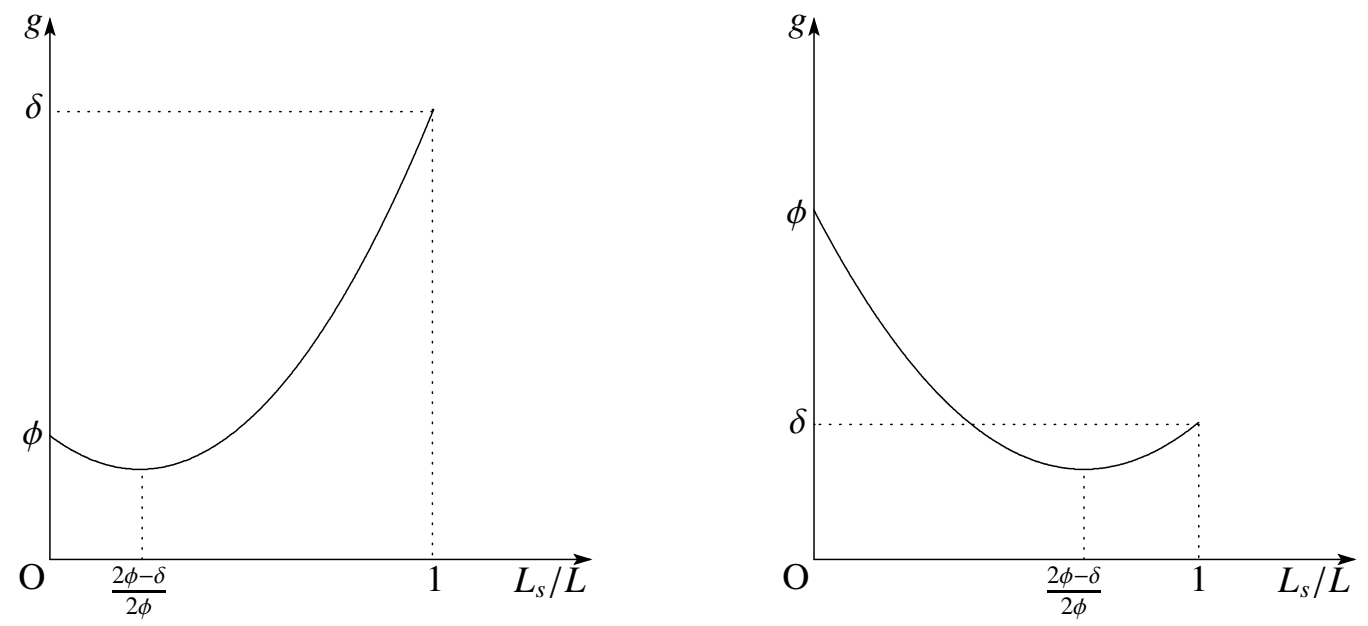

Figure 4: Relationship between $g$ and $L_{s} / L$ Figure 5: Relationship between $g$ and $L_{s} / L$ when $2 \phi>\delta$ and $\phi<\delta$ when $\phi>\delta$ 
Table 1: List of parameters

\begin{tabular}{ccccc}
\hline \hline & $\alpha$ & $\gamma$ & $\phi$ & $\delta$ \\
\hline Case 1 & 0.5 & 0.5 & 0.05 & 0.03 \\
Case 2 & 0.5 & 0.5 & 0.04 & 0.05 \\
\hline \hline
\end{tabular}

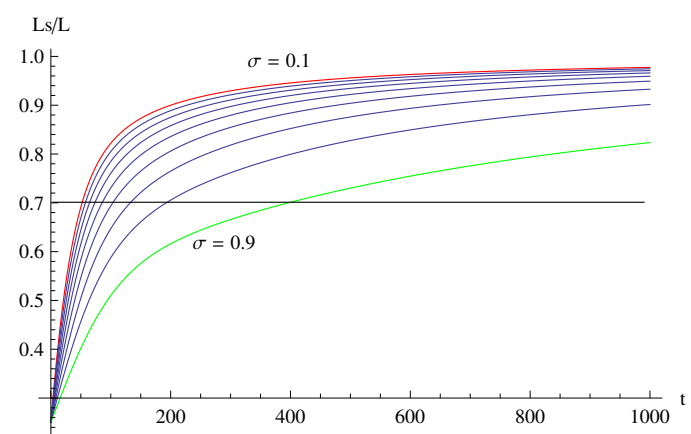

Figure 6: Dynamics of the services employment share $(\sigma<1$ and $\phi>\delta)$

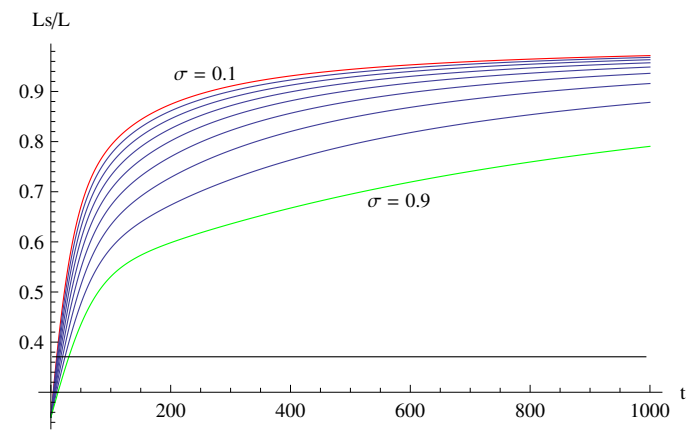

Figure 8: Dynamics of the services employment share $(\sigma<1,2 \phi>\delta$, and $\phi<\delta)$

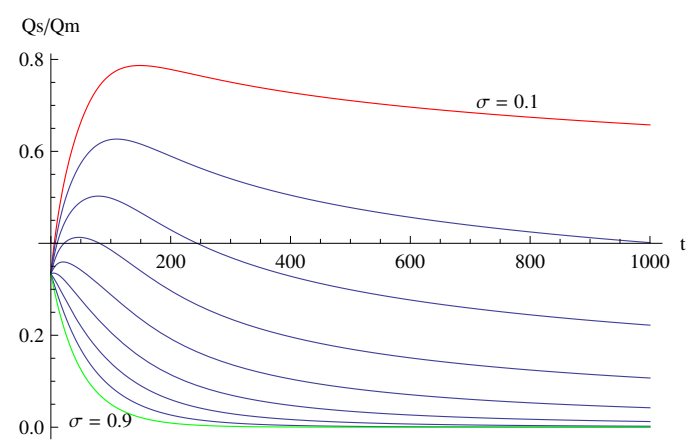

Figure 10: Dynamics of the output ratio $(\sigma<1$ and $\phi>\delta)$

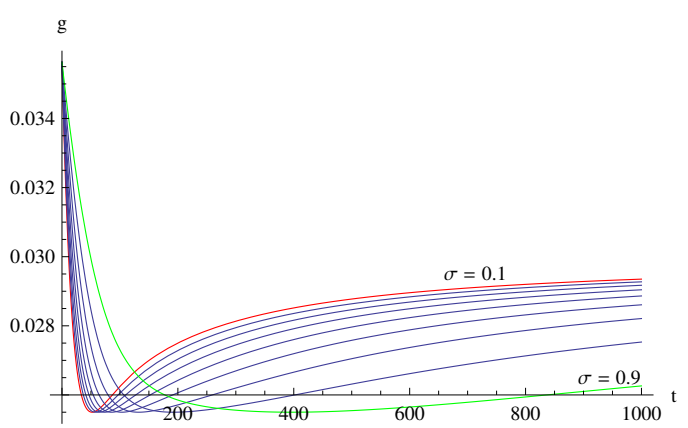

Figure 7: Dynamics of the real GDP per capita growth $(\sigma<1$ and $\phi>\delta)$

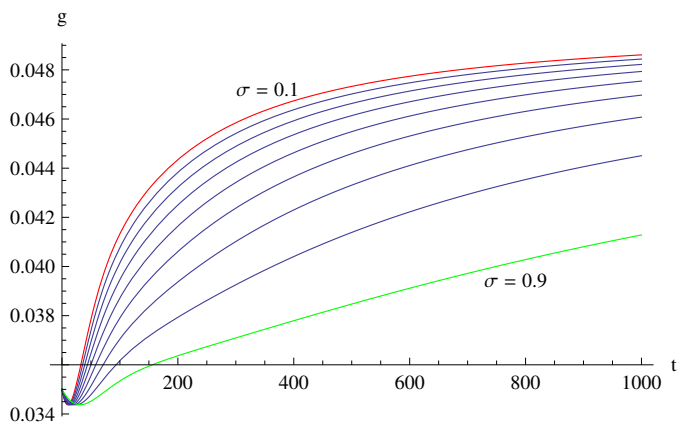

Figure 9: Dynamics of the real GDP per capita growth $(\sigma<1,2 \phi>\delta$, and $\phi<\delta)$

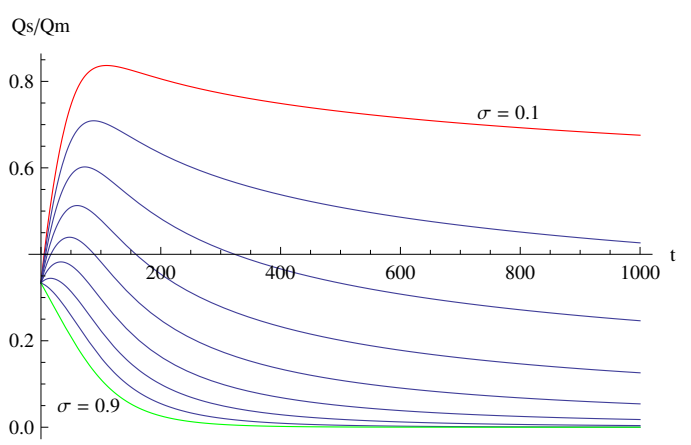

Figure 11: Dynamics of the output ratio $(\sigma<1,2 \phi>\delta$, and $\phi<\delta))$ 


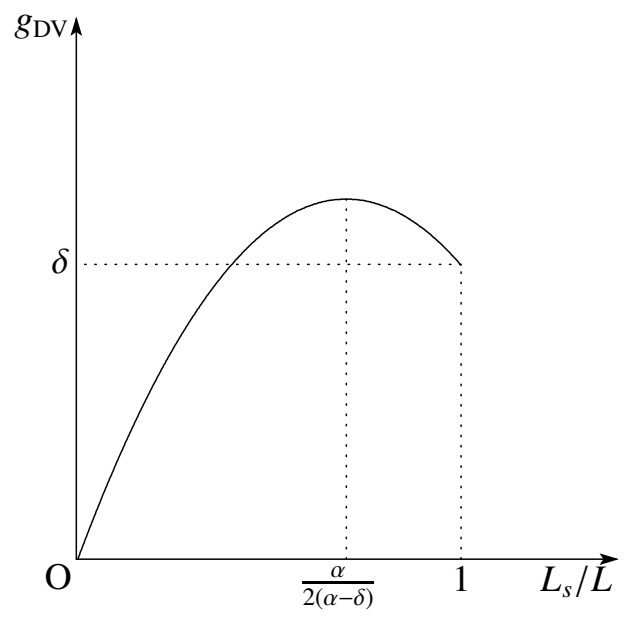

Figure 12: Relationship between $g$ and $L_{s} / L$ in De Vincenti (2007) 